\title{
Configurações
}

Revista de sociologia

\section{Reestruturação territorial e mobilidade em contexto de baixa densidade: a região da Beira Interior em Portugal}

Territorial restructuring and mobility in the context of low density: The region of Beira Interior in Portugal

Restructuration territoriale et de la mobilité dans le contexte de bas densité: La région de Beira Interior au Portugal

\section{Domingos Vaz}

\section{OpenEdition}

\section{Journals}

\section{Edição electrónica}

URL: http://journals.openedition.org/configuracoes/2117

DOI: $10.4000 /$ configuracoes. 2117

ISSN: 2182-7419

\section{Editora}

Centro de Investigação em Ciências Sociais

Edição impressa

Data de publição: 1 Junho 2013

Paginação: 25-42

ISBN: 1646-5075

ISSN: 1646-5075

\section{Refêrencia eletrónica}

Domingos Vaz, « Reestruturação territorial e mobilidade em contexto de baixa densidade: a região da Beira Interior em Portugal », Configurações [Online], 11 | 2013, posto online no dia 22 setembro 2014, consultado o 19 abril 2019. URL : http://journals.openedition.org/configuracoes/2117 ; DOI : 10.4000/ configuracoes. 2117

Este documento foi criado de forma automática no dia 19 Abril 2019.

(c) CICS 


\section{Reestruturação territorial e mobilidade em contexto de baixa densidade: a região da Beira Interior em Portugal}

Territorial restructuring and mobility in the context of low density: The region of Beira Interior in Portugal

Restructuration territoriale et de la mobilité dans le contexte de bas densité: La région de Beira Interior au Portugal

Domingos Vaz

\section{Introdução}

1 Este texto é uma contribuição para equacionar algumas das principais transformações territoriais da região da Beira Interior, aqui definida como o conjunto das três sub-regiões NUT III (Beira Interior Sul, Cova da Beira e Beira Interior Norte). Pretende-se, fundamentalmente, conhecer a evolução deste território em termos de dinâmica demográfica, de evolução habitacional e de movimentos pendulares, considerando os desafios para o futuro. A informação estatística dos Censos 2011 e a consulta de dados existentes de trabalhos publicados permitiram analisar indicadores de avaliação da situação demográfica, de mobilidade regional e da evolução do parque habitacional, evidenciando que a região se encontra confrontada com velhos e novos problemas, todos eles a exigir reflexão nas novas questões que colocam, tendo em vista assegurar um futuro sustentável.

2 Assente numa abordagem qualitativa dos indicadores, identificam-se debilidades e realçam-se aspetos intrínsecos ao eixo Guarda-Covilhã-Fundão-Castelo Branco, e equaciona-se o papel prospetivo das suas cidades, podendo 


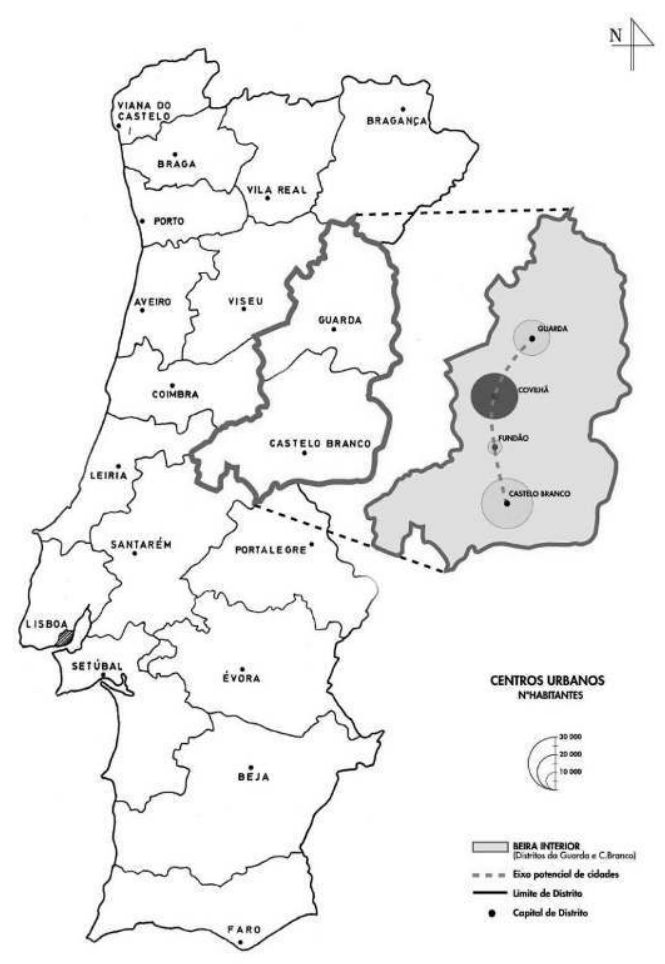

FIgURA 1. REgIÃO DA BEIRA INTERIOR NO PAÍS

estabelecer-se a partir delas uma visão estratégica, uma coordenação de instrumentos de ordenamento e desenvolvimento, com parcerias e contratualização entre atores públicos, associativos e privados. Para enquadrar o problema em análise, procede-se a uma breve reflexão em torno dos conceitos de policentrismo, de rede, de competitividade territorial, sustentabilidade e de região funcional, com as suas dimensões e implicações de política. Finalmente, procedemos a algumas considerações finais, em termos de análise estratégica, económica e político-institucional.

\section{Demografia e estruturação habitacional}

No último decénio intercensitário a Beira Interior perdeu em média cerca de três mil habitantes ao ano, registando a maioria dos concelhos perdas acima dos $10 \%$. As perdas de maior incidência percentual ocorreram nos concelhos de perfil essencialmente rural, onde as variações populacionais negativas foram superiores a $10 \%$. No distrito de Castelo Branco a quebra geral foi de 5,8\%. Apenas dois concelhos, os de Castelo Branco e de Vila de Rei, ganham população, cerca de um e três por cento, respetivamente. As perdas no distrito da Guarda são mais acentuadas (10,5\%); apenas na Guarda e em Trancoso a descida foi inferior a 10\%, já que todos os restantes concelhos têm descidas demográficas superiores. Neste contexto geral excetuam-se os concelhos que têm como sede as principais cidades, onde a população estabilizou ou registou perdas demográficas menos acentuadas: Castelo Branco cresce $1 \%$, a Covilhã perde $5 \%$, o Fundão perde $7,2 \%$ e a Guarda perde $2,9 \%$. São estes os principais focos de alguma resistência à tendência estrutural de despovoamento que grassa em toda a região. Maior densidade económica e acesso a uma rede de serviços públicos de saúde e de ensino têm feito a diferença para que o declínio se atenue nestes espaços urbanos. 
Os resultados dos censos de 2011 evidenciam, em paralelo com a perda de população, o envelhecimento populacional: a quebra de nascimentos e o aumento da esperança de média de vida, com muitos jovens entre os 20 e os 30 anos a deixarem o interior, preferindo fixar-se no litoral.

\begin{tabular}{|c|c|c|c|c|c|c|}
\hline \multirow[b]{2}{*}{ Sub-Regiões } & \multicolumn{3}{|c|}{ 1991-2001 } & \multicolumn{3}{|c|}{ 2001-2011 } \\
\hline & $\begin{array}{c}\text { Tx. } \\
\text { Cresc. } \\
\text { Efetivo }\end{array}$ & $\begin{array}{c}\text { Tx. } \\
\text { Cresc. } \\
\text { Natural }\end{array}$ & $\begin{array}{c}\text { Tx. } \\
\text { Cresc. } \\
\text { Migratório }\end{array}$ & $\begin{array}{c}\text { Tx. } \\
\text { Cresc. } \\
\text { Efetivo }\end{array}$ & $\begin{array}{c}\text { Tx. } \\
\text { Cresc. } \\
\text { Natural }\end{array}$ & $\begin{array}{c}\text { Tx. } \\
\text { Cresc. } \\
\text { Migratório }\end{array}$ \\
\hline $\begin{array}{l}\text { Beira } \\
\text { Interior } \\
\text { Norte }\end{array}$ & $-2,70 \%$ & $-5,80 \%$ & $3,10 \%$ & $-9,50 \%$ & $-7,60 \%$ & $-1,90 \%$ \\
\hline $\begin{array}{l}\text { Beira } \\
\text { Interior Sul }\end{array}$ & $-3,60 \%$ & $-7,50 \%$ & $3,90 \%$ & $-4,20 \%$ & $-8,40 \%$ & $4,20 \%$ \\
\hline $\begin{array}{l}\text { Cova da } \\
\text { Beira }\end{array}$ & $0,50 \%$ & $-4,00 \%$ & $4,50 \%$ & $-6,20 \%$ & $-4,40 \%$ & $-1,90 \%$ \\
\hline
\end{tabular}

Quadro 1 Taxas de Crescimento da População Regional

Fonte: Censos, 2001 e 2011

Em 1981, 17,8 \% da população regional era constituída por pessoas com 65 ou mais anos. Em trinta anos esta proporção subiu dez pontos percentuais, passando a ser de 27,5\% em 2011. A proporção dos idosos ultrapassou e mais do que duplicou a dos jovens com menos de 15 anos (11,7\%). Mais grave ainda, o índice de envelhecimento é elevadíssimo. Existem municípios na Beira Interior Sul, caso de Vila Velha de Ródão, com 529 idosos para 100 jovens, e Idanha-a-Nova, onde essa relação é de 453 idosos para 100 jovens. Nos municípios urbanos e devido à polarização regional que exercem, esse índice é menos acentuado: Guarda $(152,1)$, Castelo Branco $(187,9)$, Covilhã $(192,3)$ e Fundão $(235,7)$ (Fonte: Pordata e Censos, 1981 e 2011). Os indicadores relativos à fecundidade e à estrutura da população evidenciam que a região se encontra confrontada com a baixa fecundidade e um envelhecimento acentuado da população. Importará refletir nas novas questões que estes desafios colocam, com vista a assegurar um futuro sustentável.

$\mathrm{Na}$ Beira Interior existem oito cidades nas três NUTS III sub-regionais, onde se estima que se concentrem cerca de $42 \%$ da população residente na região. Destacam-se deste conjunto as cidades da Guarda, Covilhã, Fundão e Castelo Branco por atingirem valores de população residente mais elevados e que fazem impulsionar os valores de população residente nas três sub-regiões.

A Cova da Beira concentra a população urbana mais numerosa, com quase metade $(49,1 \%)$ dos seus residentes a viver nas suas duas cidades: Covilhã e Fundão. Na situação intermédia encontra-se a Beira Interior Sul, com cerca de $47,5 \%$ da população residente a viverem na sua única cidade, Castelo Branco, que se aproxima dos 35000 habitantes. A Beira Interior Norte detém cerca de um terço da sua população residente em cidades. Esta é das três sub-regiões a que detém as cidades menos populosas (Pinhel, Sabugal, Trancoso e Meda) que, em nenhum dos casos, ultrapassa o limiar dos três mil habitantes. 


\begin{tabular}{|c|c|c|c|c|c|c|}
\hline \multirow[t]{2}{*}{ NUT III } & \multicolumn{2}{|c|}{$\begin{array}{l}\text { População } \\
\text { Residente }\end{array}$} & \multirow{2}{*}{$\begin{array}{c}\text { Variação } \\
(\%)\end{array}$} & \multirow{2}{*}{$\begin{array}{c}\text { Cidades } \\
\text { N. }{ }^{\circ}\end{array}$} & \multicolumn{2}{|c|}{$\begin{array}{c}\text { População Residente } \\
\text { nas Cidades }\end{array}$} \\
\hline & 2001 & 2011 & & & 2011 & $\%$ \\
\hline $\begin{array}{l}\text { Beira } \\
\text { Interior } \\
\text { Norte }\end{array}$ & 115325 & 104417 & $-9,5$ & 5 & 34039 & 32,6 \\
\hline $\begin{array}{l}\text { Cova da } \\
\text { Beira }\end{array}$ & 93579 & 87869 & $-6,1$ & 2 & 43143 & 49,1 \\
\hline $\begin{array}{l}\text { Beira } \\
\text { Interior Sul }\end{array}$ & 78123 & 75028 & $-3,9$ & 1 & 35638 & 47,5 \\
\hline TOTAL & 287027 & 267314 & $-6,8$ & 8 & 112820 & 42,2 \\
\hline
\end{tabular}

QUADRO 2. POPULAÇÃo RESIDENTE NAS CIDADES DA BEIRA INTERIOR, 2011

Fonte: INE, Censo de 2011 e apuramento próprio

Apesar da diminuição geral da população, o parque habitacional da Beira Interior manteve a trajetória de crescimento. $O$ número de alojamentos cresceu no último decénio e de forma generalizada na região, assim como o número de edifícios. A região dispõe de mais $7 \%$ de edifícios e $9 \%$ de alojamentos destinados à habitação. $O$ acréscimo de alojamentos familiares nas quatro cidades principais foi: Castelo Branco (9,5\%), Covilhã (15,3\%), Fundão (5,8\%) e Guarda (6,9\%).

O número de famílias ao nível da região é de 109 880, registando uma ligeira subida $(0,7 \%)$ face a 2001, muito aquém da média nacional que foi de $12 \%$ na década. No plano dos quatro principais municípios da região, o número de famílias registou acréscimos principalmente na Covilhã $(4,4 \%)$, Castelo Branco ( $8 \%$ ) e Guarda $(2,4 \%)$, e diminuiu no Fundão (-0,9\%). Por seu turno, o número médio de pessoas por família assume o valor de 2,4 em Castelo Branco, Fundão e Covilhã e de 2,6 na Guarda (Quadro 3).

\begin{tabular}{|l|c|c|c|c|c|c|}
\hline \multirow{2}{*}{$\begin{array}{c}\text { Principais } \\
\text { Municípios }\end{array}$} & \multicolumn{3}{|c|}{ Alojamentos } & \multicolumn{3}{c|}{ Famílias } \\
\hline Guarda & 2001 & 2011 & Variação & 2001 & 2011 & Variação \\
\hline Covilhã & 30627 & 27894 & $6,9 \%$ & 16064 & 16444 & $2,4 \%$ \\
\hline Fundão & 20849 & 22058 & $5,8 \%$ & 12120 & 12011 & $-0,9 \%$ \\
\hline Castelo Branco & 35027 & 38382 & $9,5 \%$ & 21555 & 23277 & $8 \%$ \\
\hline
\end{tabular}

QUADRO 3. EVOLUÇÃo dOS ALOJAMENTOS E dAS FAMíLIAS ENTRE 2001 E 2011

Fonte: INE, Censos de 2001 e 2011 
11 A tendência da dinâmica construtiva em alta estava já presente num estudo do INE e da DGOTDU do fi $m$ da década de noventa (2000), que evidenciava a dinâmica construtiva de habitação, com base em dados oficiais de licenças concedidas pelas cidades médias. Em relação ao concelho da Guarda, o maior dinamismo construtivo verificava-se nas três principais freguesias urbanas, sendo evidenciada uma maior tendência para construção em altura, com menos fogos mas de maior dimensão. No concelho da Covilhã, apesar de as construções novas serem o principal tipo de obra, a sua percentagem regista um valor significativamente inferior à média das cidades médias, sendo mesmo um dos mais baixos de toda a região centro. Da mesma forma, os prédios mais altos concentram-se nas freguesias mais centrais. Simultaneamente o número de reconstruções é o mais elevado da região centro, sobretudo em muitas das freguesias limítrofes do concelho. Algumas freguesias não nucleares (Boidobra, Canhoso, Teixoso e Tortosendo) cresceram de forma determinante, expandindo a cidade para este, oeste e sul. Por sua vez, Castelo Branco tinha sido uma das cidades que cresceram sobretudo em área dos fogos. Castelo Branco e Alcains eram as freguesias urbanas com mais acentuado crescimento, e a expansão fez-se na direção norte-noroeste do concelho.

Um outro estudo de Carvalho (2008), tendo por amostra territorial um conjunto de 27 municípios do norte e centro interiores do País, dava conta de que entre 1981 e 2001 o número de fogos tinha aumentado $34 \%$, e a população diminuído $14 \%$; enquanto o número de agregados familiares quase não se modificava $(-1 \%)$, o que implicitamente significava uma tendência para um menor número de pessoas em cada agregado familiar. Em termos da oferta e procura de habitação, através de apuramentos estatísticos baseados em dois indicadores (a variação do número de pessoas comparado com o do número de fogos existentes), foi possível ponderar, através da média de indivíduos por agregado, o aumento/diminuição do excesso/deficit de fogos. Os municípios mais populosos (Guarda, Covilhã, Fundão e Castelo Branco) continuavam a registar uma incidência forte do fenómeno de urbanização, embora na Covilhã ela se verificasse de forma dispersa pelas freguesias limítrofes do tradicional perímetro urbano. Nos restantes municípios, com cidades médias, as taxas de variação da população urbana entre as duas décadas indicavam um fenómeno de concentração no antigo centro urbano, ao contrário do que sucedia na Covilhã. Admitia-se, a partir da informação estatística, que nas duas últimas décadas do século XX a população e a construção de habitação tinham evoluído em sentido oposto, construindo-se (aparentemente) mais habitações que o necessário.

O fenómeno era particularmente evidente nos maiores municípios - Castelo Branco, Guarda, Covilhã e Fundão - que já entre 1995 e 2001 revelavam a mais significativa variação populacional positiva (urbanização e despovoamento da parte rural do concelho), o que pode explicar, de alguma forma, o excesso de oferta de habitação como resultado da criação de fortes expectativas nos agentes e promotores imobiliários. Em termos geográficos todos eles são contíguos nos distritos de Castelo Branco e da Guarda, o que não deixa de indiciar o efeito polarizador da autoestrada (A23). Os municípios com maior número de habitações vagas são também os mais populosos, com Castelo Branco no top ranking (3093) confrontado com um total de novas construções de 2808 unidades. Segue-se a Guarda (3563) para 1763 novas habitações, e depois a Covilhã numa posição intermédia (2653) apesar das cerca de duas mil novas habitações. 


\section{Dinâmica regional}

14 A aferição dos movimentos pendulares quotidianos merece especial atenção, uma vez que através da sua análise é possível aceder à dinâmica das relações intermunicipais determinadas por razões de trabalho ou estudo da população residente. Em termos relativos, a análise da informação do INE evidencia que, no contexto da região, os movimentos pendulares registavam os valores mais elevados entre os municípios internos à respetiva sub-região (NUT III) na qual estão inseridos, como era expectável. A este nível de agregação espacial os dados evidenciam a centralidade da Cova da Beira e o efeito de contiguidade geográfica entre as sub-regiões. Verifica-se que os fluxos da Beira Interior Norte assumem valores na ordem dos $12,5 \%$ com a Cova da Beira e de cerca de $3 \%$ com a Beira Interior Sul. Os fluxos da Cova da Beira detêm um valor de $16,7 \%$ com a Beira Interior Sul e de cerca de $10 \%$ com a Beira Interior Norte. Por sua vez, a Beira Interior Sul tem os valores mais signifi cativos com a Cova da Beira $(14,5 \%)$ e apenas $2,5 \%$ com a Beira Interior Norte (Quadro 4).

\begin{tabular}{|c|c|c|c|c|c|c|}
\hline $\begin{array}{l}\text { Origem / } \\
\text { Destino }\end{array}$ & $\begin{array}{l}\text { Beira } \\
\text { Interior } \\
\text { Norte }\end{array}$ & $\begin{array}{c}\text { Cova da } \\
\text { Beira }\end{array}$ & $\begin{array}{l}\text { Beira } \\
\text { Interior } \\
\text { Sul }\end{array}$ & $\begin{array}{c}\text { Outro } \\
\text { Município } \\
\text { País }\end{array}$ & Estrangeiro & Total \\
\hline $\begin{array}{l}\text { Beira } \\
\text { Interior } \\
\text { Norte }\end{array}$ & $\begin{array}{c}3583 \\
(36,7 \%)\end{array}$ & $\begin{array}{c}1226 \\
(12,5 \%)\end{array}$ & $\begin{array}{c}275 \\
(2,8 \%)\end{array}$ & $\begin{array}{c}4011 \\
(41,1 \%)\end{array}$ & $\begin{array}{c}652 \\
(6,7 \%)\end{array}$ & $\begin{array}{c}9747 \\
(100 \%)\end{array}$ \\
\hline $\begin{array}{l}\text { Cova da } \\
\text { Beira }\end{array}$ & $\begin{array}{c}842 \\
(9,8 \%)\end{array}$ & $\begin{array}{c}3462 \\
(40,4 \%)\end{array}$ & $\begin{array}{c}1436 \\
(16,7 \%)\end{array}$ & $\begin{array}{c}2321 \\
(27 \%)\end{array}$ & $\begin{array}{c}504 \\
(5,8 \%)\end{array}$ & $\begin{array}{c}8565 \\
(100 \%)\end{array}$ \\
\hline $\begin{array}{l}\text { Beira } \\
\text { Interior } \\
\text { Sul }\end{array}$ & $\begin{array}{c}124 \\
(2,5 \%)\end{array}$ & $\begin{array}{c}725 \\
(14,5 \%)\end{array}$ & $\begin{array}{c}1089 \\
(21,7 \%)\end{array}$ & $\begin{array}{c}2713 \\
(54,2 \%)\end{array}$ & $\begin{array}{l}354 \\
(7 \%)\end{array}$ & $\begin{array}{c}5005 \\
(100 \%)\end{array}$ \\
\hline
\end{tabular}

QUADRO 4. MOVIMENTOS PENDULARES ENTRE AS SUB-REgIÕES DA BEIRA INTERIOR (2011)

Fonte: Censos 2011, Ativos mais Estudantes

Se tomarmos como unidade espacial de análise o município, tendo em vista analisar as relações entre os quatro municípios urbanos principais, a primeira constatação em termos relativos respeita ao efeito polarizador das cidades nos respetivos municípios que, nos casos de Castelo Branco e da Guarda, se traduz por elevados valores percentuais das deslocações pendulares internas. Denota-se que os municípios da Covilhã e do Fundão registam as trocas de movimentos pendulares mais significativos. Castelo Branco detém valores semelhantes com o Fundão e um valor mais residual com a Guarda. A Guarda detém um valor de cerca de $2 \%$ (437 deslocações maioritariamente por razões de estudo) com a Covilhã, e de menor significado com o Fundão, que regista um valor inferior ao verificado com Castelo Branco. O Fundão detém valores já com algum significado com a Covilhã (cerca de dois terços das 1168 deslocações são por razões de trabalho), com Castelo Branco $(4,4 \%)$ e mais residual com a Guarda. A Covilhã detém o fluxo maioritário 
com o Fundão, sobretudo por razões de trabalho $(4,5 \%)$, sendo os valores com Castelo Branco e a Guarda bastante inferiores mas de algum significado em termos absolutos e equilibrados (Quadro 5).

\begin{tabular}{|c|c|c|c|c|c|}
\hline $\begin{array}{l}\text { Origem / } \\
\text { Destino }\end{array}$ & Castelo Branco & Fundão & Covilhã & Guarda & Total \\
\hline $\begin{array}{l}\text { Castelo } \\
\text { Branco }\end{array}$ & $\begin{array}{c}28888 \\
(97,7 \%) \\
{[A-69,5 \% ;} \\
\text { E-30,5\%] }\end{array}$ & $\begin{array}{c}268 \\
(0,9 \%) \\
{[A-90 ; E-10]}\end{array}$ & $\begin{array}{c}335 \\
(1,1 \%) \\
{[\mathrm{A}-55 ; \mathrm{E}-45]}\end{array}$ & $\begin{array}{c}66 \\
(0,2 \%) \\
{[\mathrm{A}-68 ; \mathrm{E} 32]}\end{array}$ & $\begin{array}{c}29557 \\
(100) \\
{[\mathrm{A}-69 ; \mathrm{E} 31]}\end{array}$ \\
\hline Fundão & $\begin{array}{c}626 \\
(4,4 \%) \\
{[A-70 ; E-30]}\end{array}$ & $\begin{array}{c}12201 \\
(86,6 \%) \\
{[\mathrm{A}-68 ; \mathrm{E}-32]}\end{array}$ & $\begin{array}{c}1168 \\
(8,3 \%) \\
{[\mathrm{A}-71 ; \mathrm{E}-29]}\end{array}$ & $\begin{array}{c}93 \\
(0,6 \%) \\
{[\mathrm{A}-58 ; \mathrm{E}-42]}\end{array}$ & $\begin{array}{c}14088 \\
(100) \\
{[\mathrm{A}-68 ; \mathrm{E} 32]}\end{array}$ \\
\hline Covilhã & $\begin{array}{c}555 \\
(2 \%) \\
{[\mathrm{A}-65 ; \mathrm{E}-35]}\end{array}$ & $\begin{array}{c}1182 \\
(4,5 \%) \\
{[A-90 ; E-10]}\end{array}$ & $\begin{array}{c}24372 \\
(92 \%) \\
{[\mathrm{A}-67 ; \mathrm{E}-33]}\end{array}$ & $\begin{array}{c}360(1,4 \%) \\
{[A-84 ;} \\
\text { E-16] }\end{array}$ & $\begin{array}{c}26469 \\
(100) \\
{[\mathrm{A}-68 ; \mathrm{E} 32]}\end{array}$ \\
\hline Guarda & $\begin{array}{c}96 \\
(0,4 \%) \\
{[A-55 ; E-45]}\end{array}$ & $\begin{array}{c}50 \\
(0,2 \%) \\
{[\mathrm{A}-82 ; \mathrm{E}-18]}\end{array}$ & $\begin{array}{c}437 \\
(1,9 \%) \\
{[\mathrm{A}-48 ; \mathrm{E} 52]}\end{array}$ & $\begin{array}{c}22264 \\
(97,4 \%) \\
{[A-67 ; \text { E-33] }}\end{array}$ & $\begin{array}{c}22847 \\
(100) \\
{[\mathrm{A}-67 ; \mathrm{E} 33]}\end{array}$ \\
\hline
\end{tabular}

QUADRO 5. MOVIMENTOS PENDULARES ENTRE MUNICÍPIOS COM CIDADES DA BEIRA INTERIOR (2011)

Fonte: Censos 2011, Ativos [A] mais Estudantes [E]

A análise da comparação intercensitária (Censos de 2001 e 2011) dos quatro municípios com cidades médias pode ser realizada a partir da informação representada nos Gráficos (1 a 4) que se seguem. Assim, é possível aferir e comparar os movimentos pendulares quotidianos, por razões de trabalho ou estudo, internos e com origem em cada um dos 
principais municípios e com destino nos restantes três (os valores do Censo de 2011 estão marcados a bold). 


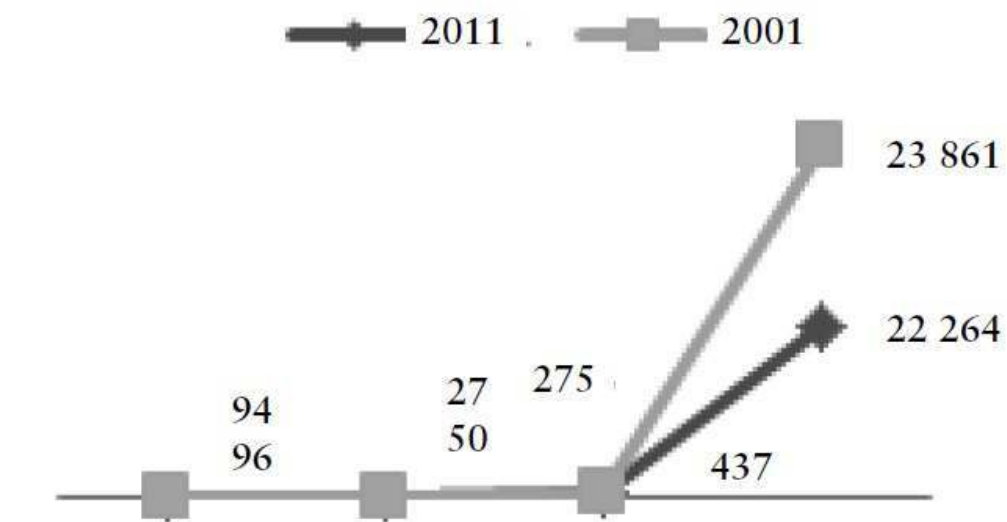

Castelo Branco Fundão Covilhã Guarda

\section{FIgURA 2. MUNICÍPIO DA GUARDA}

Fonte: Censos 2001, 2011
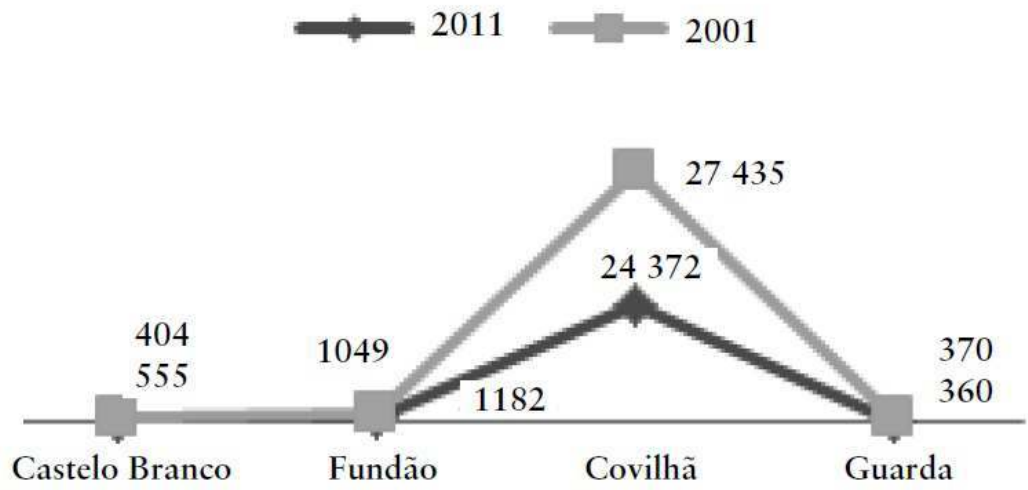

Figura 3. Município da Covilhã

Fonte: Censos 2001, 2011

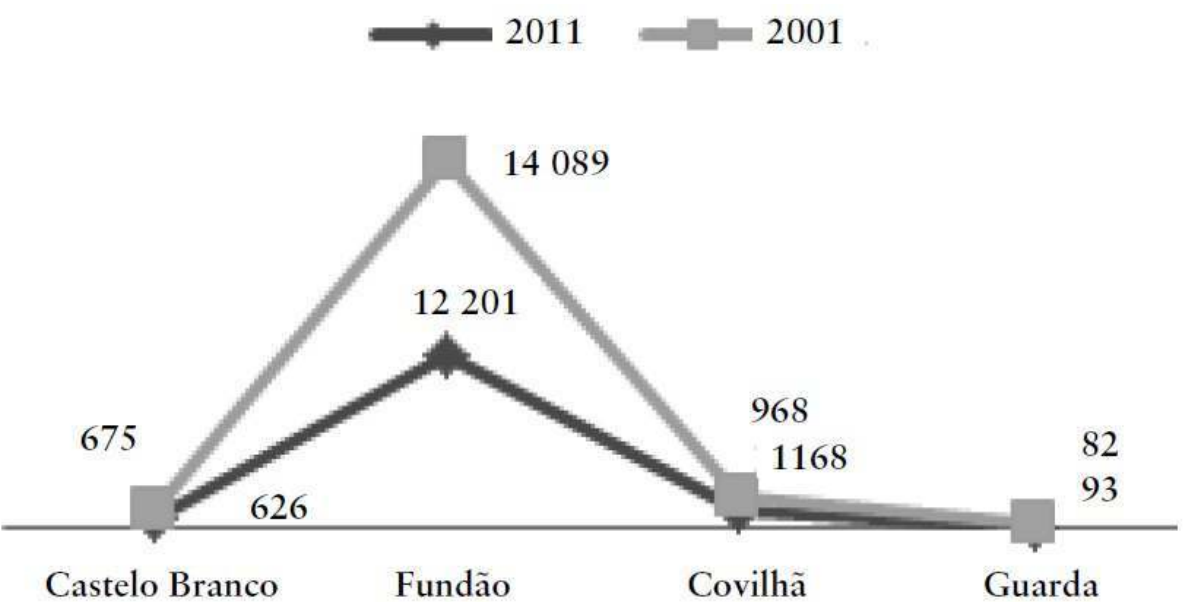

Figura 4. Município do Fundão

Fonte: Censos 2001, 2011 


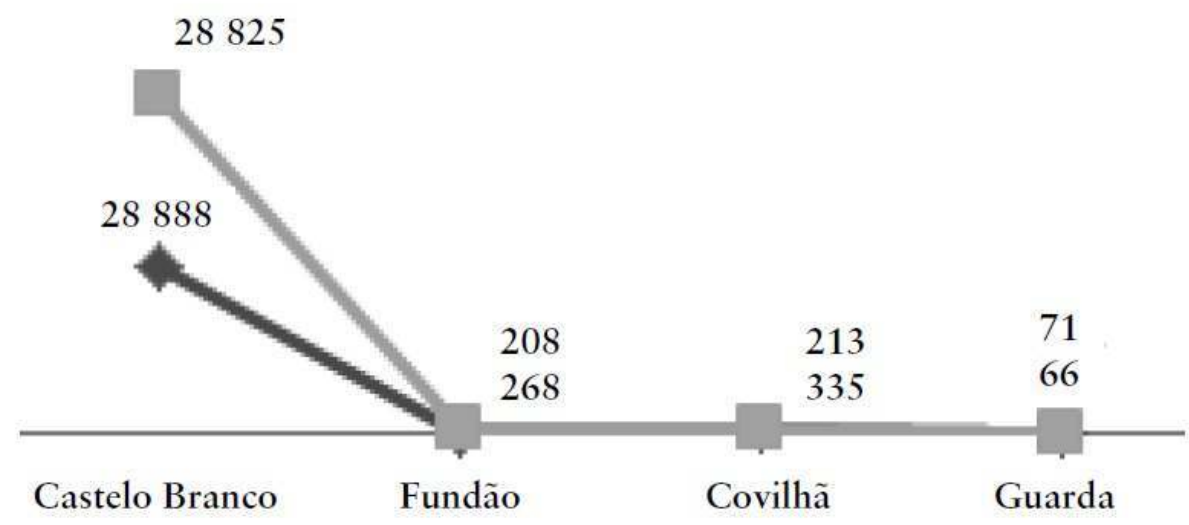

Figura 5. Município de Castelo Branco

Fonte: Censos 2001, 2011

17 A informação evidencia que no conjunto destes quatro municípios os ativos e os estudantes registaram um decréscimo global de $-6 \%$ no último decénio. Para este decréscimo contribuíram em primeiro lugar a Covilhã (que decresceu -18\%), o Fundão $(-11 \%)$ e a Guarda (-6\%). Castelo Branco excetua-se desta tendência, denotando estabilidade dado o ligeiro acréscimo que regista $(+0,8 \%)$. Os fluxos com origem na Guarda (Gráfico 1) com destino a Castelo Branco denotam estabilidade, observando-se que para o Fundão duplicaram e para a Covilhã cresceram cerca de $60 \%$. Da Covilhã para Castelo Branco e para o Fundão o fluxo observou acréscimos, respetivamente, de $37 \%$ e de $13 \%$, enquanto para a Guarda decresceu ligeiramente (Gráfico 2). Por sua vez, verifica-se que o fluxo do Fundão em direção à Covilhã cresceu 21\%, para a Guarda $13 \%$ e para Castelo Branco baixou -7\% (Gráfico 3). Finalmente observa-se (Gráfico 4) que o fluxo de Castelo Branco registou com algum significado um acréscimo em direção à Cova da Beira. Assim, este fluxo teve o maior acréscimo com a Covilhã (57\%) e de seguida com o Fundão (29\%), decrescendo ligeiramente com a Guarda.

\section{Policentrismo regional}

Os princípios gerais para uma política de ordenamento do território com base na noção de policentrismo foram apresentados em 1999 pelo Conselho Europeu de Ministros responsáveis pelo ordenamento do território e o desenvolvimento institucionalizado da União Europeia (no âmbito do Desenvolvimento do Espaço Comunitário, CEC, 1999). É uma perspetiva que preconiza o desenvolvimento de uma plataforma para a conexão e integração de cidades (especialmente pequenas e médias) e para o incremento do desenvolvimento socioeconómico regional e que contribui para mitigar as disparidades (inter e intrarregionais), mas também para criar as condições adequadas à internacionalização em mercados globais e redes (Carmo, 2013).

É importante referir não só a importância das cidades propriamente ditas, mas a sua integração no território envolvente, como é desenvolvido por Alves (2007) em relação ao continente português. De facto, não é possível compreender a dinâmica de uma cidade sem atender à região e ao sistema urbano-regional em que a mesma se insere. Um relatório da UE (CE, 2004) sustenta que as cidades lideram a competitividade económica e 
que os sistemas urbanos são os motores do desenvolvimento regional. De acordo com este raciocínio, podemos enfatizar que as regiões ganhadoras integram habitualmente as cidades mais competitivas.

A mundialização e o declínio do Estado-nação induziram as condições para a emergência de novos territórios estratégicos: as regiões e as cidades. É reconhecido que estas escalas espaciais se tornaram importantes arenas do desenvolvimento e que os níveis subnacionais se traduzem nas unidades geográficas mais apropriadas para a afirmação da competitividade territorial.

21 As cidades são ainda os espaços com a maior responsabilidade para contribuir para a prossecução da sustentabilidade global do planeta. De acordo com a "Carta da Sustentabilidade das Cidades Europeias" (Aalborg, 1994), a cidade é a maior unidade com capacidade para gerir os numerosos desequilíbrios urbanos que afetam o mundo moderno: arquitetónicos, sociais, económicos, políticos, de recursos naturais e ambientais; mas são também a menor unidade na qual se poderão resolver estes problemas, de uma forma eficaz, integrada, global e sustentável. Daí que se devam integrar os princípios da sustentabilidade em todas as políticas e fazer das especificidades de cada cidade a base de estratégias de desenvolvimento regional e local. O conceito de cidade sustentável tem como objetivo principal o bem-estar da população de longo prazo, o que compreende a satisfação das suas necessidades económicas e materiais, mas também as de ordem cultural, social e ambiental.

As cidades médias podem assumir-se como âncoras das regiões envolventes, contribuindo para a organização de territórios mais equilibrados, assumindo a função de instrumentos de desenvolvimento regional. Mas, pela sua dimensão demográfica e funcional, continuam a ser demasiado pequenas para assegurarem o seu papel no sistema urbano $\mathrm{e}$ para se afirmarem nacional e internacionalmente. Contudo, a hierarquia urbana tradicional está a dar lugar à hierarquia de uma rede de cidades ou de um território em rede, e os processos de inovação e de mundialização exigem às cidades e aos territórios a sua integração económica, social e cultural em "redes de cidades" com vocações funcionais semelhantes ou complementares. A questão das redes é importante devido à ausência de dimensão crítica de grande parte destas cidades. Os espaços mais amplos detêm frequentemente ativos significativos em termos de infraestruturas materiais e imateriais, o que lhes atribui maior potencial de atratividade e competitividade.

De notar, no entanto, que, de acordo com a CE (2004), uma análise das redes de cooperação entre cidades indica a existência de uma forte rede de grandes metrópoles no centro da Europa e uma débil, ou mesmo ausente, cooperação estratégica entre pequenas e médias cidades europeias deficitárias quanto a acessibilidades e, ao mesmo tempo, em posição de marginalização do ponto de vista do desenvolvimento. A Europa caracteriza-se "por uma estrutura urbana mais policêntrica e menos concentrada“; só 7\% das pessoas vivem em cidades com mais de cinco milhões de habitantes, contrariamente a $25 \%$, nos EUA; e só cinco cidades da UE se incluem na lista das cem maiores metrópoles do mundo (CCE, 2011: 5).

24 Em territórios de baixa densidade esta questão é decisiva devido à ausência de dimensão crítica de grande parte destas cidades, pelo que se torna importante promover o apoio à estruturação de redes urbanas e de sistemas urbanos de proximidade para a valorização partilhada de recursos, potencialidades e conhecimento. 

centros urbanos relativamente estabilizados, sobressaindo algumas cidades relativamente importantes à escala regional, das quais se destacam Castelo Branco, Covilhã, Fundão e Guarda, cujos perímetros urbanos foram completamente alterados, dando lugar a uma dispersão geográfica das funções, nomeadamente a residencial nas áreas suburbanas e periurbanas. 0 resultado deste processo, particularizado pela terciarização, pelo despovoamento rural e pela melhoria das acessibilidades regionais e nacionais, conduziu a uma configuração polinucleada de cidades de média dimensão e na estruturação de nós e eixos urbanos, sendo da maior relevância o seu protagonismo no quadro global de interioridade onde se localizam (PROT, 2011).

29 A visão polinucleada surge como podendo ancorar uma estratégia de desenvolvimento regional pelos seguintes motivos: trata-se de uma região periférica, e por isso encontra-se desprovida de muitas das características das regiões centrais; a pequena dimensão dos centros urbanos e a fraca diversidade da sua base urbana inibem a criação e a alimentação de economias externas; o progressivo esvaziamento populacional das áreas de influência condiciona o crescimento dos centros urbanos; o aumento da acessibilidade leva à sobreposição das áreas de influência dos centros urbanos, levando-os a especializarem-se 
em determinadas funções ou atividades, valorizando o potencial de conjunto (Vaz, 2008). Partindo de uma visão crítica sobre a organização espacial, tem pertinência a reflexão sobre a importância do eixo urbano polinucleado Guarda-Castelo Branco para o desenvolvimento da região. As vantagens em apostar numa estratégia de organização territorial polinuclear são evidentes:

i) Reforço da coesão e da identidade regional, e maior enraizamento cultural da população;

ii) Melhor aproveitamento das diversidades locais e maior valorização do património natural e cultural;

iii) Maior integração do território, ao dispersar as oportunidades de emprego, de valorização pessoal, os equipamentos, etc., tendo, no entanto, presente o máximo de eficácia na sua localização;

iv) Maior flexibilidade locacional para atividades e funções;

v) Diminuição dos riscos de congestionamento e das pressões dos usos e atividades sobre o espaço urbano, melhorando o ambiente;

Dinuição dos movimentos migratórios de longa distância;

vii) A polinucleação como evidência empírica da organização do território que interessa promover e consolidar.

No entanto a concretização destes objetivos coloca a questão da necessidade de uma recomposição institucional. Novos problemas e realidades necessitam de respostas adequadas por instituições que cooperem entre si, de modo a aproveitar a acessibilidade existente e a proximidade entre os centros urbanos, bem como as potencialidades de cada um deles, baseadas em complementaridades, maximizando o potencial de conjunto, atendendo à especialização em funções e atividades para as quais apresentem vantagens comparativas no seio da rede e que seja racional na utilização dos recursos públicos. E, bem assim, promover a solidariedade entre os centros urbanos e com o resto da região procurando esbater rivalidades espaciais e mobilizar a população e os agentes em torno de um "projeto regional".

38 As transformações são favorecidas pela atuação de fatores de mudança e de reestruturação, mas também da mobilidade, dos novos modos de vida e dos fenómenos de governância, entre eles, o dos projetos políticos municipais e seus protagonistas e dos atores da sociedade civil. A geografia emergente coloca em evidência uma maior interdependência entre territórios, nas várias escalas espaciais, e a necessidade de novas abordagens interpretativas das dinâmicas e dos problemas económicos, sociais e ambientais do interior.

Impulsionar a cooperação supramunicipal é tanto mais oportuno, quanto a atual conjuntura aconselha a uma racionalização de recursos, equacionada numa lógica estratégica de aglomeração de coletividades territoriais de proximidade que possam conferir a territórios de baixa densidade uma maior densificação das suas redes sociais, económicas, educacionais e culturais. A complementaridade entre as cidades significa retirar benefícios do mesmo tipo de estruturas e investimentos para densificar as redes e reforçar as condições de atratividade de um território em condições de interioridade mas contíguo. E, sobretudo, pensar que o papel de cada cidade não é reduzir-lhe importância ou limitar-lhe a estruturação por estratégias de absorção do que lhe está mais ou menos 
próximo, mas antes contribuir para valorizar os pontos de articulação do conjunto do sistema territorial.

\section{Considerações finais}

40 O território objeto de análise quanto a indicadores demográficos e de estruturação urbana e habitacional tem registado uma evolução dos alojamentos habitacionais bastante acima das necessidades definidas exclusivamente pela variação da população e em sentido inverso. Esta é uma realidade generalizada a toda a região, mas tem maior expressão nos municípios mais populosos, onde se fez mais sentir o efeito de atração urbana das populações rurais circundantes.

41 A informação disponível levanta algumas pistas pertinentes de investigação que seria interessante desenvolver com uma base georreferenciada de dados e que permitisse identificar a variação das formas de ocupação dos fogos face às famílias existentes e o destino funcional dos eventuais fogos em excesso: estarão eles vagos ou trata-se de segundas habitações? E que especificidades sociais e urbanas assumirá o fenómeno da suburbanização nas quatro principais cidades da região, no fundo em pequenas e médias cidades?

Devido ao relativo afastamento entre si, estas cidades não constituem no seu conjunto uma estrutura urbana complexa e contínua, mas o seu protagonismo é da maior relevância no quadro global de interioridade onde se localizam. São-lhes reconhecidos alguns elementos estratégicos para o ordenamento e o desenvolvimento territorial, a dinamização de uma rede multipolar com potencial para sustentar o desenvolvimento regional policêntrico, ou quanto à posição geográfica nas ligações com Espanha e com a Europa, permitindo apostas inovadoras no aproveitamento das oportunidades que podem ser abertas nestas escalas geográficas.

Importa evidenciar que ao nível da região a noção de tempo sofreu transformações, influenciada pelas novas acessibilidades e com maior significado nos centros urbanos e nas relações entre eles, tornando mais próxima a ideia de uma rede de cidades que a sociedade civil vai progressivamente densificando. $\mathrm{E}$ faz sentido discutir como estimular a cooperação entre cidades e seus polos de conhecimento em torno de projetos concretos que reforcem a atratividade e a complementaridade das cidades mas também da região. No fundo importa interrogar: que estratégia se quer ver implementada na região integrada numa estratégia nacional e europeia? Caberá a este território de baixa densidade e seus centros urbanos organizarem-se coletivamente e traçarem um caminho próprio, e não esperarem pelos desígnios nacionais e europeus. As instituições de ensino superior sediadas na região ocupam um papel determinante na produção e fixação de capital humano altamente qualificado, mas também na determinação crescente do perfil produtivo, social e cultural das cidades da região, em especial, as que posicionam a sua visão estratégica num futuro sustentável baseado no estabelecimento de modalidades de concertação institucional e no abandono de soluções polarizadas apenas por um dos tipos de atores ou segmentos territoriais.

No contexto português as cidades médias não são fortes em densidade de stock (base económica, dimensão demográfica...), mas mantêm a carga identitária que as distingue. Por isso, torna-se fundamental a identificação e promoção dos fatores intangíveis do desenvolvimento como visão estratégica de atratividade urbana e regional. A este 
propósito um documento elaborado pela Comissão Europeia enfatiza: “As características genéricas das cidades de pequena e média dimensão, em especial a sua escala humana, a qualidade de vida, a sociabilidade dos seus bairros, a sua integração geográfica e o seu carácter histórico, constituem em muitos aspetos um ideal de urbanismo sustentável" (CCE, 2011: 5; Leipzig, 2007). As cidades de pequena e média dimensão são, por conseguinte, essenciais para evitar o despovoamento rural e o êxodo para as metrópoles e são indispensáveis para o "desenvolvimento regional equilibrado, a coesão e a sustentabilidade do território europeu". Na Beira Interior os padrões sub-regionais de povoamento atingem alguma polarização em contraponto com o despovoamento, a baixa densidade e a recessão demográfica. A rede policêntrica de cidades médias acaba por diferenciar as cidades do eixo urbano Guarda-Covilhã-Fundão-Castelo Branco dos pequenos centros, sobretudo as sedes de município, importantes para o ordenamento do território e pelo seu papel de âncoras das regiões envolventes, contribuindo para a organização de territórios mais equilibrados (PNPOT, 2007).

A realidade dá mostras de um maior número de trocas e interações populacionais entre os centros urbanos, mas ao nível do poder local, a condicionante eleitoral levou as cidades a pensarem sobretudo no imediato. E a ausência de uma perspetiva de âmbito regional que tenha a ousadia de pensar e criar possibilidades de desenvolvimento de longo prazo reduz a própria dimensão geográfica dos problemas e das oportunidades. Neste aspeto caberia ao poder político assumir o papel instrumental facilitador da dinâmica no terreno e que a sociedade vai construindo. A resistência decorre em grande parte da importância histórica do "município" enquanto importante unidade territorial administrativa. 0 discurso político local enfatiza essa realidade também como "unidade básica da democracia" de proximidade e bem posicionada para gerir os interesses do eleitorado e conhecer as suas necessidades. Do ponto de vista político, o município, além de moldar as decisões e modos de intervenção, constitui a base da legitimação do poder político local. Do ponto de vista sociológico, é uma partição que vai além de uma simples divisão territorial; ela contribui para a criação de uma entidade à qual nos encontramos profundamente ligados: condiciona modos de pensamento, caracterizações e classificações envolvendo distinções que aplicamos nas nossas práticas quotidianas. Existe uma correspondência entre divisão e efeito de divisão que é preciso interpretar. É esta, também, uma análise e um debate que importa detalhar e estimular sobre a dinâmica tendencial para um funcionamento mais articulado da região e os processos e fenómenos que o condicionam.

46 Em termos económicos, existe a perceção de que nas últimas décadas a política regional se concentrou nas condições dos fatores, na acessibilidade física e nas organizações de suporte. Ingredientes necessários, mas não suficientes. As regiões menos desenvolvidas viram os seus défices de dinamismo económico, social e competitivo compensados pelo desenvolvimento das atividades não transacionáveis, em particular no sector social da economia e nos serviços administrativos. Tal modelo parece conhecer claros sinais de esgotamento que colocam interrogações quanto à sustentação, prosperidade $\mathrm{e}$ convergência das economias das regiões menos desenvolvidas, profundamente afetadas por uma erosão demográfica, envelhecimento e fixação de população, pondo em causa a sua sustentabilidade futura. Assim, a situação atual não dispensa a reorientação da política regional dirigida às economias menos desenvolvidas, visando compensar os constrangimentos dos efeitos de aglomeração a que estão sujeitas as regiões de baixa densidade. Parece-nos que importa refletir sobre a perspetiva que privilegia o papel dos 
atores, do adensamento das suas relações, marcadas por comportamento de copresença, e da capacidade de gestão de fluxos geradores de ganhos de dimensão, em complementaridade com a ponderação de opções estratégicas de política regional centrada no recurso ao conceito de sectores-chave ou polos de crescimento, com forte enfoque na criação de emprego.

Será interessante a conceptualização baseada nas "regiões funcionais" para levar a cabo diagnósticos, definir estratégias de desenvolvimento territorial ou programar e implementar intervenções integradas em espaços que não coincidem com delimitações administrativas, superando os custos decorrentes de visões geograficamente fragmentadas.

\section{BIBLIOGRAPHY}

AALBORG Charter (1994), Charter of European Cities \& Towns towards Sustainability (as approved by the participants at the European Conference on Sustainable Cities \& Towns in Aalborg, Denmark on 27 May 1994). Available at: http://ec.europa.eu/environment/urban/pdf/aalborg_charter.pdf [Data de acesso: 7/4/2010].

ALVES, Rui (2007), Políticas de planeamento e ordenamento do território no Estado Português, Textos Universitários de Ciências Sociais e Humanas, Lisboa: Fundação Calouste Gulbenkian.

CARMO, R. M. (2013), "Polycentrism as a Multi-Scalar Relationship between Urban and Rural Areas: The Case of Portugal", European Planning Studies, 21 (2): 149-166.

CARVALHO, Pedro (2008), "Forma urbana e desenvolvimento sustentável: Ensaiando um ponto de partida para os territórios de fronteira", Domingos Vaz (org.), Cidade e Território: Identidades, Urbanismos e Dinâmicas Transfronteiriças, Lisboa: Editora Celta: 203-226.

CCE (2011), Cities of Tomorrow. Challenges, visions, ways toward. Disponível em: http://ec.europa.eu/ regional_policy/sources/docgener/studies/pdf/citiesoftomorrow/citiesoftomorrow_fi nal.pdf [Data de acesso: 7/12/2012].

CEC (1999), ESDP - European Spatial Development Perspective: Towards Balanced and Sustainable Development of the Territory of the EU (Luxembourg: Office for Official Publications of the European Communities). Available at: http://ec.europa.eu/regional_policy/sources/docoffi c/official/ reports/pdf/sum_en.pdf [Data de acesso: 8/2/2013].

COMISSÃO de Coordenação de Desenvolvimento Regional do Centro (2011),PROT-Centro, Plano Regional de Ordenamento Territorial do Centro: Coimbra.

COUTO, Alcino (2007), "Dinâmicas e mutações estruturais na raia central”, Felisberto M. Reigado e António F. Matos (eds.), Dinâmicas de desenvolvimento e valorização dos recursos endógenos na Beira Interior, Vila Nova de Foz Côa: PlaniCôa: 105-139.

DIREÇÃO-GERAL do Ordenamento do Território e do Desenvolvimento Urbano e Instituto Nacional de Estatística (2000), Pressão Construtiva nos Concelhos com Cidades Médias, Volume 2, Lisboa. 
EUROPEAN COMMISSION (2004), A New Partnership for Cohesion. Available at: http//:ec.europa.eu/ regional_policy/sources/docoffi c/offi cial/reports/cohesion3/cohesion3_pt.htm [Data de acesso: $21 / 05 / 2007]$.

FERRÃO, João (1997), Rede urbana instrumento de equidade, coesão e desenvolvimento?, Colóquio: A Política de Cidades, série "Estudos e Documentos", Lisboa: CES - Conselho Económico e Social. Disponível em: http://www.ces.pt/download/564/ColPolCidades.pdf [Data de acesso:7/07/2012].

FERRÃO, João e Teresa Marques (2003), Sistema urbano nacional. Síntese, Lisboa: DGOTDU/ Ministério das Cidades, Ordenamento do Território e Ambiente.

FERRÃO, João (coord.), (2012), Regiões funcionais, relações urbano-rurais e política de coesão pós-2013, Relatório final, Lisboa: Instituto de Ciências Sociais Disponível em: http://www.qren.pt/np4/np4/? newsId=1334\&fi leName=regioes_funcionais.pdf [Data de acesso: 5/10/2013].

LEIPZIG Charter (2007), Leipzig Charter on Sustainable European Cities. Available at: http:// www.eukn.org/binaries/eukn/policy/2007/8/leipzig-charta-adr-pt.pdf [Data de acesso: 13/02/2012].

MAOTDR - Ministério do Ambiente, do Ordenamento do Território e do Desenvolvimento Regional (2007), PNPOT - Programa Nacional da Política de Ordenamento do Território (Lisboa: MAOTDR).

REIGADO, Marques (2007), "Modelo e estratégias de desenvolvimento", Felisberto M. Reigado e António F. Matos (eds.), Dinâmicas de desenvolvimento e valorização dos recursos endógenos na Beira Interior, Vila Nova de Foz Côa: PlaniCôa: 341-381.

VAZ, Domingos e Rui Alves (2012), “Transformações recentes nos territórios do eixo GuardaCastelo Branco", Atas do VII Congresso Português de Sociologia, Lisboa, APS. ISBN: 978-989-97981-0-6. Disponível em http://www.aps.pt/VII_Congresso/ [Data de acesso: 5/4/2013].

VAZ, Domingos (2008), “Que rumo para as cidades do Interior?", Domingos Vaz (org.), Cidade e Território: Identidades, Urbanismos e Dinâmicas Transfronteiriças, Lisboa: Celta Editora: 1-32.

\section{ABSTRACTS}

Este texto equaciona algumas das principais transformações da área de influência do eixo Guarda-Castelo Branco. Pretende-se conhecer a evolução destes territórios em termos de dinâmica demográfica, de evolução habitacional e das relações de interdependência entre segmentos territoriais, considerando os desafios para o futuro. As principais cidades do eixo constituíram-se desde cedo como pontos nodais que estruturaram o território regional e são perspetivadas como elementos decisivos para o reequilíbrio do território, no quadro do policentrismo regional.

This text aims at characterizing and analyzing the main urban and territorial changes under the influence area of the cities Guarda-Castelo Branco. It is basically intended to know the evolution of these territories concerning their population dynamics, urban occupation and the relations of interdependence between territorial segments, bearing in mind the challenges for the future. The main cities of this area have soon been established as central points that structured the regional territory and in this text have been assumed as crucial parts for the rebalance of the inland territory, in terms of the construction of the regional polycentrism.

Cet article vise à caractériser et analyser les grandes transformations urbaines et territoriales de la zone d'influence de l'axe urbain Guarda-Castelo Branco. L'objectif est de connaître l'évolution 
de ces zones en termes de dynamique de la population et de l'occupation urbaine et les relations d'interdépendance entre les segments territoriales, compte tenu des défi s pour l'avenir.

Les villes de cet axe urbain constitué dès points nodaux qui ont structuré le territoire régional et dans ce texte sont conceptualisées comme la clé de rééquilibrage du territoire de l'intérieur, dans la construction du polycentrisme régional.

INDEX

Palavras-chave: Abandono agrícola, multifuncionalidade, espaço social rural, pós-ruralidade Mots-clés: Développement régional, la durabilité, flux régionaux, polycentrisme

Keywords: Regional development, regional flows, polycentrism, sustainability

\section{AUTHOR}

\section{DOMINGOS VAZ}

Departamento de Sociologia da Universidade da Beira Interior \& investigador integrado do CesNova

dmvaz@sapo.pt 